\title{
Pemilihan Bahasa dalam Ranah Publik Kaum Migran di Kota Semarang ${ }^{1}$
}

\author{
Mujid Farihul Amin \\ Fakultas Ilmu Budaya, Universitas Diponegoro \\ mujidfib@gmail.com
}

\begin{abstract}
Based on the results of this study it is known that in the public sphere most migrants in the city of Semarang use Indonesian more often than their mother tongue. However, it turns out that there are some migrants who still retain their native language, namely the traditional migrants who live in the villages. In the public sphere for migrants who are married and already working, in communicating with colleagues, superiors and subordinates more often use Indonesian in both official and informal situations. In the public sphere (such as schools and workplaces) for migrants with child status, most choose to use Indonesian to communicate well with peers, teachers, administrative staff, library staff, as well as gardeners and janitors.
\end{abstract}

Keywords: Migrants; language selection; public sphere; Semarang City.

\section{Intisari}

Kaum migran di Kota Semarang sebagian besar lebih sering menggunakan bahasa Indonesia dibandingkan dengan bahasa daerah atau ibu mereka. Meskipun demikian, ternyata ada beberapa kaum migran yang masih mempertahankan bahasa daerahnya/ibunya yaitu pada kalangan migran tradisional yang menetap di daerah perkampungan. Pada ranah publik untuk migran berstatus kawin/menikah dan sudah bekerja, dalam berkomunkasi dengan kolega, atasan, maupun bawahan lebih sering menggunakan bahasa Indonesia baik dalam situasi resmi maupun tidak resmi. Pada ranah publik (seperti sekolah dan tempat kerja) bagi migran berstatus anak, mayoritas memilih menggunakan bahasa Indonesia untuk berkomunikasi baik dengan teman sebaya, guru, staff adiministrasi, pegawai perpustakaan, maupun tukang kebun dan petugas kebersihan

Kata kunci: Kaum migran; pemilihan bahasa; ranah publik; Kota Semarang.

\section{Pendahuluan}

Perpindahan penduduk dari satu daerah ke daerah lain biasanya dipicu untuk memenuhi berbagai kebutuhan bersifat material, selain sosial, psikologis, dan politis (Mantra, 2000; 2015). Selain faktor-faktor tersebut, ada satu faktor yang sering terabaikan yaitu dari faktor budaya, terutama aspek bahasa. Penduduk yang juga sekaligus penutur yang melakukan migrasi, kalau dipandang dari sudut kebahasaan, ternyata tidak selamanya pada daerah tujuan yang memiliki bahasa daerah atau bahasa ibu yang sama, tetapi sering juga ke

\footnotetext{
${ }^{1}$ Tulisan ini merupakan bagian dari penelitian RPP berjudul "Pergeseran dan Pemertahanan Bahasa Ibu bagi Migran di Kota Semarang" yang dibiayai Dibiayai dengan Sumber Dana: Selain APBN LPPM RKAT Universitas Diponegoro Tahun Anggaran 2018 dan 2019
} 
daerah tujuan atau masyarakat bahasa yang berbeda, baik dalam tataran dialek maupun bahasa.

Dengan berada dalam lingkungan yang berbahasa ibu berbeda akan menuntut pemakaian bahasa yang berbeda daripada bahasa ibu di daerah asalnya. Ketika hidup dalam kondisi demikian, migran tersebut dihadapkan pada beberapa pilihan yaitu menggunakan bahasa nasional (dalam konteks Indonesia adalah bahasa Indonesia), bahasa ibunya jika berkomunikasi dengan penutur yang memiliki bahasa ibu yang sama, atau beradaptasi menggunakan bahasa ibu (bahasa daerah) daerah tujuan migrasi.

Peristiwa kebahasaan akan lebih kompleks lagi bagi migran generasi selanjutnya. Generasi ketiga kaum migran biasanya sudah menjadi monolingual, yakni hanya menguasi bahasa daerah (Negara) tujuan atau dalam konteks Indonesia kemungkinan hanya menguasai bahasa daerah tujuan dan tentu bahasa nasional (Indonesia) (cf.Sumarsono, 2013; Chaer dan Agustina,2010).

Berbagai kemungkinan pemakaian bahasa seperti tergambar di atas, mengindikasikan adanya proses pemilihan bahasa dalam tindak tutur. Ada banyak faktor berpengaruh terhadap pemilihan bahasa, seperti partisipan, situasi, ranah, dan tujuan (Fishman, 1972; Sumarsono, 2013, Chaer dan Agustina, 2010). Bila berkomunikasi dengan penutur lain yang asalnya dari daerah yang sama, maka pilihan bahasa yang dipakai adalah bahasa ibu atau nasional, jika dengan penutur yang berbahasa ibu berbeda kemungkinan pilihannya adalah bahasa nasional (bahasa Indonesia) atau salah satu bahasa ibu penutur jika keduanya menguasai bahasa ibu tersebutn atau salah satunya. Suasana/Situasi juga turut berperan menentukan pilihan bahasa, selain ranah dan tujuan.

Masalah yang dikaji dalam penelitian ini adalah bagaimana pemilihan bahasa dalam ranah publik kaum migran di Wilayah Kota Semarang. Tujuan penelitian ini adalah untuk mengetahui bagaimana bagaimana pemilihan bahasa dalam ranah publik kaum migran di kota Semarang.

\section{Metode Penelitian}

Tahapan yang dilalui dalam penelitian ini mencakup: (1) pengumpulan data, (2) analisis data, dan (3) penyajian hasil analisis.

Terkait dengan pengumpulan data, dua jenis data yang digunakan dalam penelitian ini yaitu data sekunder dan primer. Untuk data primer yang digunakan data kuantitatif dan 
kualitatif. Data primer kuantitatif diperoleh dengan wawancara terstruktur. Adapun pengumpulan data primer kualitatif dikumpulan dengan metode observasi/simak dan wawancara mendalam.

Dalam tahap analisis data digunakan analisis kuantitatif dan kualitatif. Untuk analisis kuantitatif dgunakan statistik deskriptif (tabel distribusi frekuensi tunggal dan silang) dan untuk analisis kualitatif digunakan analisis deskriptif, kategoris, dan pemaknaan teoretik.

\section{Hasil dan Pembahasan}

Pemilihan bahasa kaum migran di Kota Semarang pada ranah publik dijelaskan sebagai berikut:

1. Komunikasi di Tempat Kerja dengan Kolega dalam Situasi Resmi

Dalam komunikasi sehari-hari di tempat kerja dengan kolega dalam situasi resmi, responden lebih banyak menggunakan bahasa Indonesia dibanding bahasa ibu mereka. Responden menggunakan bahasa Indonesia dengan presentase sebanyak 32,7 persen, sedangkan responden dengan bahasa ibu hanya sekitar lima persen. Dari presentase tersebut dapat dilihat bahwa dalam situasi resmi, responden lebih sering menggunakan bahasa Indonesia dengan koleganya, karena mereka menganggap bahasa Indonesia lebih mudah digunakan untuk komunikasi sehari-hari dan lebih mudah dipahami dibanding bahasa ibu mereka.

Selain menggunakan bahasa Indonesia dan bahasa ibu, responden juga menggunakan kombinasi dari kedua bahasa tersebut untuk berkomunikasi dengan rekan kerja di situasi resmi. Namun untuk kombinasi dari bahasa ibu dan bahasa Indonesia ini memiliki presentase yang cukup sedikit. Bahasa kombinasi keduanya tapi lebih sering menggunakan bahasa ibu sebanyak empat koma lima persen, sedangkan kombinasi keduanya tapi lebih sering bahasa Indonesia sebanyak tiga koma enam persen. Dari pemaparan di atas sesuai dengan tabel berikut.

Tabel 4.22 Komunikasi di Tempat Kerja dengan Kolega dalam Situasi Resmi

\begin{tabular}{|r|l|r|l|}
\hline Kategori & Kategori & Jumlah & persen \\
\hline 1 & bahasa ibu & 6 & 5.5 \\
\hline
\end{tabular}




\begin{tabular}{|c|c|c|c|}
\hline 2 & bahasa Indonesia & 36 & 32.7 \\
\hline 3 & kombinasi keduanya tetapi lebih sering bahasa ibu & 5 & 4.5 \\
\hline 4 & kombinasi keduanya tetapi lebih sering bahasa Indonesia & 4 & 3.6 \\
\hline Total & & 51 & 46.4 \\
\hline \multirow[t]{2}{*}{ System } & & 59 & 53.6 \\
\hline & & 110 & 100.0 \\
\hline
\end{tabular}

Sumber: Data Primer, 2016

2. Komunikasi di Tempat Kerja dengan Kolega dalam Situasi Tidak Resmi

Dalam situasi tidak resmi, responden berkomunikasi dengan kolega lebih banyak menggunakan bahasa Indonesia dibanding bahasa ibu. Responden menggunakan bahasa Indonesia sebanyak 14,5 persen, sedangkan menggunakan bahasa ibu sebanyak delapan koma dua persen. Jumlah tersebut berbanding sangat jauh, karena mereka dalam situasi tidak resmi pun lebih banyak menggunakan bahasa Indonesia karena alasan lebih mudah dipahami bersama jika dibanding dengan bahasa ibu mereka. Mereka beranggapan bahasa ibu lebih susah dipahami karena mereka berasal dari tempat yang berbeda-beda.

Responden dalam berkomunikasi dengan kolega kerja dalam situasi tidak resmi juga menggunakan kombinasi bahasa keduanya. Berbeda dengan situasi resmi, dalam situasi tidak resmi ini responden cukup banyak menggunakan bahasa kombinasi keduanya. Untuk responden dengan bahasa kombinasi keduanya tetapi lebih sering berbahasa ibu sebanyak 10 persen. Untuk responden menggunakan bahasa kombinasi keduanya tapi lebih sering berbahasa Indonesia sebanyak 12,7 persen. Dalam hal ini responden lebih banyak menggunakan bahasa kombinasi keduanya tetapi lebih sering bahasa Indonesia dalam situasi tidak resmi. Mereka beranggapan bahasa Indonesia lebih mudah dan gampang dipahami jika dibanding dengan bahasa ibu mereka. Dari penejelasan di atas sesuai dengan tabel di bawah ini.

Tabel 4.23 Komunikasi di Tempat Kerja dengan Kolega dalam Situasi Tidak Resmi

\begin{tabular}{|r|l|r|l|}
\hline Kategori & Kategori & Jumlah & persen \\
\hline 1 & bahasa ibu & 9 & 8.2 \\
\hline 2 & bahasa Indonesia & 16 & 14.5 \\
\hline
\end{tabular}




\begin{tabular}{|c|c|c|c|}
\hline 3 & kombinasi keduanya tetapi lebih sering bahasa ibu & 11 & 10.0 \\
\hline 4 & kombinasi keduanya tetapi lebih sering bahasa Indonesia & 14 & 12.7 \\
\hline Total & & 50 & 45.5 \\
\hline \multirow[t]{2}{*}{ System } & & 60 & 54.5 \\
\hline & & 110 & 100.0 \\
\hline
\end{tabular}

Sumber: Data Primer, 2016

\section{Komunikasi di Tempat Kerja dengan Bawahan dalam Situasi Resmi}

Dalam komunikasi sehari-hari di tempat kerja, responden berkomunikasi dengan bawahan dalam situasi resmi didominasi menggunakan bahasa Indonesia dan paling sedikit menggunakan bahasa ibu. Responden menggunakan bahasa Indonesia sebanyak 26,4 persen. Jumlah tersebut cukup banyak jika dibandingkan dengan bahasa ibu yaitu hanya 1,8 persen, hal tersebut menunjukan hanya beberapa responden saja yang menggunakan bahasa ibu ketika berkomunikasi dengan bawahan di tempat kerja dalam situasi resmi. Selain menggunakan bahasa ibu dan bahasa Indonesia, responden juga menggunakan bahasa kombinasi dari keduanya, baik lebih dominasi bahasa Indonesia maupun bahasa Ibu. Responden dengan kombinasi bahasa keduanya memiliki jumlah yang sama yaitu sebanyak empat koma lima persen saja. Jumlah tersebut lebih banyak jika dibandingkan dengan responden yang menggunakan bahasa ibu dalam komunikasi dengan bawahan dalam situasi resmi. Dari penjelasan di atas sesuai dengan tabel berikut.

Tabel 4.24 Komunikasi di Tempat Kerja dengan Bawahan dalam Situasi Resmi

\begin{tabular}{|r|l|r|l|}
\hline No & Kategori & Jumlah & persen \\
\hline 1 & bahasa ibu & 2 & 1.8 \\
\hline 2 & bahasa Indonesia & 29 & 26.4 \\
\hline 3 & kombinasi keduanya tetapi lebih sering bahasa ibu & 5 & 4.5 \\
\hline 4 & kombinasi keduanya tetapi lebih sering bahasa Indonesia & 5 & 4.5 \\
\hline Total & & 41 & 37.3 \\
\hline System & & 69 & 62.7 \\
\hline
\end{tabular}


\begin{tabular}{|l|r|l|}
$\mid$ & 110 & 100.0 \\
\hline
\end{tabular}

Sumber: Data Primer, 2016

4. Komunikasi di Tempat Kerja dengan Bawahan dalam Situasi Tidak Resmi

Dalam komunikasi sehari-hari dengan bawahan di tempat kerja dalam situasi tidak resmi responden lebih banyak menggunakan bahasa Indonesia dari pada menggunakan bahasa ibu maupun kombinasi bahasa keduanya. Responden menggunakan bahasa ibu dengan bawahan dalam situasi tidak resmi sebanyak 15,5 persen. Jumlah tersebut cukup banyak jika dibandingkan dengan jumlah responden yang menggunakan bahasa ibu dalam komunikasi di tempat kerja, yaitu hanya sekitar empat koma persen saja. Selain menggunakan bahasa Indonesia dan bahasa ibu, dalam komunikasi dengan bawahan di situasi tidak resmi responen juga menggunakan kombinasi bahasa keduanya baik lebih sering menggunakan bahasa Indonesia maupun lebih sering menggunakan bahasa ibu mereka. Responden yang menggunakan kombinai keduanya tapi lebih sering menggunakan bahasa Indonesia sebanyak sembilan koma satu persen. Presentase tersebut lebih banyak jika dibadingkan dengan responden yang memakai bahasa keduanya tapi lebih banyak menggunakan bahasa ibu yaitu sebanyak tujuh koma tiga persen.

Dari penjelasan di atas, responden dalam komunikasi dengan bawahan baik di situasi resmi ataupun tidak resmi lebih banyak menggunakan bahasa Indonesia dari pada bahasa ibu mereka. Mereka lebih mudah menggunakan bahasa Indonesia untuk komunikasi dengan bawahan karena mereka berasal dari bahasa ibu yang berbe-beda. Penjelasan di atas sesuai dengan tabel di bawah ini.

Tabel 4.25 Komunikasi di Tempat Kerja dengan Bawahan dalam Situasi Tidak Resmi

\begin{tabular}{|r|l|r|l|}
\hline Kategori & Kategori & Jumlah & persen \\
\hline 1 & bahasa ibu & 5 & 4.5 \\
\hline 2 & bahasa Indonesia & 17 & 15.5 \\
\hline 3 & kombinasi keduanya tetapi lebih sering bahasa ibu & 8 & 7.3 \\
\hline 4 & kombinasi keduanya tetapi lebih sering bahasa Indonesia & 10 & 9.1 \\
\hline Total & & 40 & 36.4 \\
\hline
\end{tabular}




\begin{tabular}{|l|r|r|l|}
\hline System & 70 & 63.6 \\
\hline & & 110 & 100.0 \\
\hline
\end{tabular}

Sumber: Data Primer, 2016

5. Komunikasi di Tempat Kerja dengan Atasan dalam Situasi Resmi

Dalam situasi resmi, responden berkomunikasi dengan atasan di tempat kerja menggunakan bahasa Indonesia, kombinasi bahasa Indonesia dan bahasa ibu tapi lebih sering bahasa ibu, dan menggunakan kombinasi kedua bahasa tapi lebih sering menggunakan bahasa Indonseia. Dalam berkomunikasi dengan atasan responden didominasi menggunakan bahasa Indonesia karena dianggap lebih sopan dan resmi yaitu sebanyak 32,7 persen. Sedangkan untuk bhasa kombinasi keduanya baik lebih sering bahasa ibu ataupun bahasa Indonesia hanya dua koma tujuh persen saja. Dari jumlah tersebut responden jarang menggunakan kombinasi kesdua bahasa jika berbicara dengan atasan. Responden juga tidak pernah menggunakan bahasa ibu mereka ketika berbicara dengan atasan. Hal tersebut dapat dilihat pada tabel berikut.

Tabel 4.26 Komunikasi di Tempat Kerja dengan Atasan dalam Situasi Resmi

\begin{tabular}{|l|l|r|l|}
\hline No & Kategori & Jumlah & persen \\
\hline & 1 & 0 & 0 \\
\hline 2 & bahasa ibu & 36 & 32.7 \\
\hline 3 & $\begin{array}{l}\text { kombinasi keduanya tetapi lebih sering bahasa } \\
\text { ibu }\end{array}$ & 3 & 2.7 \\
\hline & $\begin{array}{l}\text { kombinasi keduanya tetapi lebih sering bahasa } \\
\text { Indonesia }\end{array}$ & 3 & 2.7 \\
\hline Total & & 42 & 38.2 \\
\hline System & & 68 & 61.8 \\
\hline & & 110 & 100.0 \\
\hline
\end{tabular}

Sumber: Data Primer, 2016

6. Komunikasi di Tempat Kerja dengan Atasan dalam Situasi Tidak Resmi

Responden ketika berkomunikasi dengan atasan dalam situasi tidak resmi di tempat kerja lebih banyak mengggunakan bahasa Indonesia yaitu sebesar 27,3 persen. Jumlah ini cukup 
banyak jika dibandingkan dengan penggunaan kombinasi keduanya. Kombinasi keduanya tetapi lebih sering dengan bahasa ibu sebanyak enam koma empat persen dan responden dengan bahasa kombinasi keduanya lebih sering dengan bahasa Indonesia sebanyak empat koma lima persen. Dari penelitian ini responden tidak ada yang menggunakan bahasa ibunya ketika berkomunikasi dengan atasan baik di situasi resmi maupun di situasi tidak resmi. Mereka menganggap jika menggunakan bahasa ibu itu kurang sopan karena menggunakan bahasa daerah masing-masing yang tidak semua orang mengetahuinya. Dari penjelasan di atas sesuai dengan tabel berikut.

Tebel 4.27 Komunikasi di Tempat Kerja dengan Atasan dalam Situasi Tidak Resmi

\begin{tabular}{|r|l|r|l|}
\hline No & Kategori & Jumlah & persen \\
\hline 1 & bahasa ibu & 0 & 0 \\
\hline 2 & bahasa Indonesia & 30 & 27.3 \\
\hline 3 & kombinasi keduanya tetapi lebih sering bahasa ibu & 7 & 6.4 \\
\hline 4 & kombinasi keduanya tetapi lebih sering bahasa Indonesia & 5 & 4.5 \\
\hline Total & & 42 & 38.2 \\
\hline System & & 68 & 61.8 \\
\hline & & 110 & 100.0 \\
\hline
\end{tabular}

Sumber: Data Primer, 2016

7. Bahasa yang dipergunakan untuk berkomunikasi dengan teman sebaya di sekolah atau di lingkungan kerja*)

Pada tabel sebelumnya telah dijelaskan bahwa salah satu penyebab terjadinya pergeseran bahasa adalah lingkungan sekolah dan faktor ekonomi dalam hal ini berhubungan dengan lingkungan kerja. Di sekolah,biasa guru mengajarkan bahasa asing kepada para siswa, dengan demikian lambat laun siswa mulai mengkombinasikan bahasa ibu dengan bahasa asing yang diajarkan di sekolah, seiring berkembangnya waktu bahasa ibu sudah tidak lagi dipergunakan di lingkungan sekolah. Hal demikian terjadi juga di lingkungan kerja, terlebih jika tempat responden bekerja adalah kantor yang mengharuskan menggunakan bahasa Indonesia terlebih bahasa asing atau bahasa Inggris, sehingga mau tidak mau 
responden yang sebelumnya menggunakan bahasa ibu lambat laun akan terbiasa dengan bahasa di lingkungan kerja.

Persentase paling banyak pada bahasa yang dipergunakan untuk berkomunikasi dengan teman sebaya di sekolah atau di lingkungan kerja*) adalah kombinasi dari bahasa ibu dengan bahasa Indonesia tetapi lebih sering bahasa Indonesia, yakni sebesar 7,3 persen dari 18 responden yang menjawab. Hal demikian terjadi juga pada opsi bahasa Indonesia, yang mendapat perhatian responden sebesar 6,4 persen. Sudah barang tentu bahwa bahasa ibu yang paling sedikit diminati responden, yakni tercatat hanya kurang dari satu persen responden yang menggunakan bahasa ibu untuk berkomunikasi di lingkungan sekolah maupun lingkungan kerja*). Bahasa Indonesia paling banyak diminati karena bahasa Indonesia adalah bahasa persatuan bangsa Indonesia. Perhatikan tabel berikut.

Tabel 4.34 Bahasa yang dipergunakan untuk berkomunikasi dengan teman sebaya di sekolah atau di lingkungan kerja*)

\begin{tabular}{|l|l|r|l|}
\hline No & Kategori & Jumlah & Persen \\
\hline & 1 & 1 & .9 \\
\hline 2 & bahasa ibu & 7 & 6.4 \\
\hline 3 & $\begin{array}{l}\text { kombinasi keduanya tetapi lebih sering } \\
\text { bahasa ibu }\end{array}$ & 2 & 1.8 \\
\hline 4 & $\begin{array}{l}\text { kombinasi keduanya tetapi lebih sering } \\
\text { bahasa Indonesia }\end{array}$ & 18 & 16.4 \\
\hline Total & & 92 & 83.6 \\
\hline System & & 110 & 100.0 \\
\hline & &
\end{tabular}

Sumber: Data Primer, 2016

8. Bahasa yang dipergunakan (responden berstatus pelajar) berkomunikasi dengan guru di luar kegiatan belajar mengajar

Seperti halnya di sekolah, bahasa yang dipergunakan (responden berstatus pelajar) dalam berkomunikasi dengan guru di luar kegiatan belajar mengajar juga didominasi oleh bahasa Indonesia, yakni sebesar 8,2 persen dari 11 responden. Sedangkan bahasa ibu tidak mendapatkan perhatian sama sekali dari responden, artinya bahasa ibu semakin tidak diminati dan dimungkinkan terjadi kepunahan. Begitu pula dengan opsi kombinasi antara 
bahasa ibu dengan bahasa Indonesia tetapi lebih dominan bahasa ibu juga tidak menjadi minat responden untuk digunakan dalam komunikasi di lingkungan sekolah, artinya responden sudah tidak menggunakan bahasa ibu sama sekali dan berpindah ke penggunaan bahasa Indonesia. Selanjutnya, sebesar 1,8 persen dari 11 responden menjawab menggunakan bahasa ibu dan bahasa Indonesia tetapi lebih dominan bahasa Indonesia. Perhatikan tabel berikut.

Tabel 4.35 Bahasa yang dipergunakan (responden berstatus pelajar) berkomunikasi dengan guru di luar kegiatan belajar mengajar

\begin{tabular}{|c|l|r|r|}
\hline Kategori & Kategori & Jumlah & persen \\
\hline 1 & bahasa ibu & 0 & 0 \\
\hline 2 & bahasa Indonesia & 9 & 8.2 \\
\hline 3 & $\begin{array}{l}\text { kombinasi keduanya tetapi lebih sering bahasa } \\
\text { ibu }\end{array}$ & 0 & 0 \\
\hline 4 & $\begin{array}{l}\text { kombinasi keduanya tetapi lebih sering bahasa } \\
\text { Indonesia }\end{array}$ & 11 & 10.0 \\
\hline Total & & 99 & 90.0 \\
\hline System & & 110 & 100.0 \\
\hline & & & \\
\hline
\end{tabular}

Sumber: Data Primer, 2016

9. Bahasa yang digunakan (responden berstatus pelajar) dalam berkomunikasi dengan staf administrasi dan petugas perpustakaan di luar kegiatan kerja (pelayanan)

Persentase yang sama terjadi pada responden berstatus pelajar yang dominan menggunakan bahasa Indonesia dalam berkomunikasi dengan staf administrasi dan petugas perpustakaan meskipun di luar kegiatan kerja (pelayanan), yakni sebesar delapan persen dari 11 responden. Sedangkan kurang dari dua persen responden memilih opsi mengkombinasi bahasa ibu dengan bahasa Indonesia tetapi lebih sering menggunakan bahasa Indonesia. Dari data yang ada terlihat bahwa bahasa ibu sudah jarang digunakan baik dalam kegiatan di sekolah maupun di luar sekolah dan lebih didominasi oleh bahasa Indonesia. Perhatikan tabel berikut. 
Tabel 4.36 Bahasa yang digunakan (responden berstatus pelajar) dalam berkomunikasi dengan staf administrasi dan petugas perpustakaan di luar kegiatan kerja (pelayanan)

\begin{tabular}{|l|l|r|r|}
\hline Kategori & Kategori & Jumlah & Persen \\
\hline 1 & bahasa ibu & 0 & 0 \\
\hline 2 & bahasa Indonesia & 9 & 8.2 \\
\hline 3 & kombinasi keduanya tetapi lebih sering bahasa ibu & 0 & 0 \\
\hline 4 & kombinasi keduanya tetapi lebih sering bahasa Indonesia & 2 & 1.8 \\
\hline Total & & 11 & 10.0 \\
\hline System & & 99 & 90.0 \\
\hline & & 110 & 100.0 \\
\hline
\end{tabular}

Sumber: Data Primer, 2016

10. Bahasa yang digunakan (responden berstatus pelajar) dalam berkomunikasi dengan tukang kebun, petugas kebersihan, dan yang setingkat

Bahasa yang digunakan pelajar dalam berkomunikasi dengan tukang kebun, petugas kebersihan, dan yang setingkat tidak jauh berbeda dengan bahasa yang digunakan dengan guru di luar jam sekolah maupun dengan petugas perpustakaan, tetapi ada sedikit perbedaan, yakni sebesar 7,3 persen dari 11 responden menjawab menggunakan bahasa Indonesia, dan masing-masing kurang dari satu persen memilih opsi menggunakan bahasa ibu, kombinasi antara bahasa ibu dengan bahasa Indonesia tetapi lebih sering bahasa ibu, dan yang terakhir kombinasi bahasa ibu dengan bahasa Indonesia tetapi lebih dominan bahasa Indonesia. Kembali lagi ke bahasa Indonesia yang lebih dominan digunakan,baik pada situasi resmi maupun situasi tidak resmi. Perhatikan tabel berikut. 
Tabel 4.37 Bahasa yang digunakan (responden berstatus pelajar) dalam berkomunikasi dengan tukang kebun, petugas kebersihan, dan yang setingkat

\begin{tabular}{|c|l|r|r|}
\hline No & Kategori & Jumlah & \multicolumn{1}{|l|}{ Persen } \\
\hline 1 & bahasa ibu & 1 & .9 \\
\hline 2 & bahasa Indonesia & 8 & 7.3 \\
\hline 3 & $\begin{array}{l}\text { kombinasi keduanya tetapi lebih sering bahasa } \\
\text { ibu }\end{array}$ & 1 & .9 \\
\hline 4 & $\begin{array}{l}\text { kombinasi keduanya tetapi lebih sering bahasa } \\
\text { Indonesia }\end{array}$ & 1 & .9 \\
\hline Total & & 99 & 90.0 \\
\hline System & & 110 & 100.0 \\
\hline
\end{tabular}

Sumber: Data Primer, 2016

\section{Simpulan}

Berdasarkan uraian diatas dapat diambil simpulan bahwa pada ranah publik bagi migran berstatus menikah dan sudah bekerja, dalam berkomunkasi dengan kolega, atasan, maupun bawahan lebih sering menggunakan bahasa Indonesia baik dalam situasi resmi maupun tidak resmi. Pada ranah publik (seperti sekolah dan tempat kerja) bagi migran berstatus anak, sebagian besar memilih menggunakan bahasa Indonesia untuk berkomunikasi baik dengan teman sebaya, guru, staff adiministrasi, pegawai perpustakaan, maupun tukang kebun dan petugas kebersihan.

\section{Daftar Pustaka}

Amar, Rahim. 2004. "Pergeseran dan Pemertahanan Bahasa" dalam http://dlop.gov.my/dlop98/pb099jurai.htm.

Borbely, Anna. 2000. "The Process and the Factors of Language Shift and Maintenance: A Sociolinguistics Research in the Romanian Minority in Hungary”. http://e-lib.rss.cz

Borin, Lars. 2009. Linguistic resources for the languages of the world. Språkbanken, Dept. of Swedish Language, University of Gothenburg GF summer school, 26 August.

Chaer, Abdul dan Leonie Agustina. 2010. Sosiolinguistik: Perkenalan Awal. Jakarta: Rineka Cipta.

Fasold, Ralp. 1984. Sociolinguistics of Society. New York: Basil Blackwell. 
Jamzaroh., Siti, dkk, 2012. "Pergeseran Bahasa (Language Shifting) dalam Keluarga Banjar-Banjar di Kalimantan Selatan. Balai Bahasa Kalimantan Selatan.

Mantra, Ida Bagoes. 2015. Demografi Umum, Cetakan XVII. Yogyakarta: Pustaka Pelajar.

Mardikantoro, Hari Bakti. 2007. "Pergeseran Bahasa Jawa dalam Ranah Keluarga pada Mayarakat Multibahasa di Wilayah Kabupaten Brebes" dalam Humaniora, volume 19/I : 43-44.

Mbete, Aron Meko. 2003. "Bahasa dan Budaya Lokal Minoritas: Asal Muasal, Ancaman, dan Ancangan Pemberdayaan dalam Rangka PIP Kebudayaan Universitas Udayana”. Orasi Ilmiah Pengukuhan Guru Besar Unud, Bali.

Musgrave, Simon and John Hajek. 2010. "Sudanese Languages in Melbourne: Linguistic Demography and Language Maintenance". Selected Papers from the 2009 Conference of the Australian Linguistic Society, edited by Yvonne Treis \& Rik De Busser. http://www.als.asn.au.

Setyawan, Aan. 2011. "Bahasa Daerah dalam Perspektif Kebudayaan dan Sosiolinguistik: Peran dan Pengaruhnya dalam Pergeseran dan Pemertahanan Bahasa. International Seminar Languuge Maintenance and Shift, 2 Juli.

Sumarsono. 2013. Sosiolinguistik, cetakan IX. Yogyakarta: Pustka Pelajar.

Wijana, I Dewa Putu. 2013. Sosiolinguistik: Kajian Teori dan Analisis. Cetakan V. Yogyakarta: Pustaka Pelajar.

Yuliawati, Susi. 2008. "Situasi Kebahasaan di Wilayah Pangandaran: Suatu Kajian Sosiolinguistik tentang Pergeseran dan Pemertahanan Bahasa" Thesis S2 Program Studi Linguistik Unpad Bandung. 